\title{
Crystal Structures of the Cyclic Oligoesters from 6,8-Dioxabicyclo[3.2.1]octan-7-one. II. The Optically Inactive Cyclic Tetramer
}

\author{
Mikio IMAEDA, ${ }^{*}$ Isao TANAKA, ${ }^{*}$ Tamaichi ASHIDA, ${ }^{*}$ \\ Ichiro TAJIMA, ${ }^{* *}$ Masahiko OKADA, ${ }^{* *}$ \\ and Hiroshi SUMITOMO** \\ *Department of Applied Chemistry, Faculty of Engineering and \\ **Faculty of Agriculture, Nagoya University, \\ Chikusa-ku, Nagoya 464, Japan.
}

(Received August 17, 1981)

\begin{abstract}
The crystal structure of a cyclic tetramer from racemic 6,8-dioxabicyclo[3.2.1] octan-7-one was determined. The tetramer crystallized with $1.5 \mathrm{CH}_{3} \mathrm{CN}$ solvate per molecule in a monoclinic space group $\mathrm{C} 2 / c$, with $a=44.53(3), b=5.997(2), c=22.562(9) \AA, \beta=$ 108.41(3) ${ }^{\circ} ; D c=1.338, D m=1.34 \mathrm{~g} / \mathrm{cm}^{3}, Z=8$. The final $R$ was 0.099 for 3120 observed data $(|F o| \geqq 3 \sigma(F o))$. Contrary to the expectation of a meso compound having an inversion center or a $\overline{4}$ axis within the molecule, this tetramer was found to be a racemic mixture of a pair of optically active enantiomers. The molecule showed an approximate four-fold symmetry with a roughly square 20-membered ring. The tetramer formed inclusion complex with an acetonitrile molecule accommodated in its central cavity by dipole-dipole interaction. Another acetonitrile molecule was found on the crystallographic two-fold axis surrounded by six tetramer molecules.
\end{abstract}

KEY WORDS Crystal Structure / Cyclic Oligoester / 6,8-Dioxabicyclo[3.2.1]octan-7-one Cyclic Oligomer / Inclusion Complex /

6,8-Dioxabicyclo[3.2.1] octane-7-one (DBOO) is a bicyclic lactone, having a tetrahydropyran ring. By ring opening oligomerization at $-40^{\circ} \mathrm{C}$, it produces ten-, twenty-, and twenty-five-membered macrocyclic oligoesters (dimer, tetramer, and pentamer). ${ }^{1-3}$ These consist of tetrahydropyran rings and ester groups joined alternatively and are structurally similar to some extent to those of nactins.

In oligomerization reactions, optically active DBOO, (+)-(1 R,5S)-6,8-dioxabicyclo[3.2.1]octan7 -one, gives only optically active tetra- and pentamer, while racemic DBOO gives optically inactive di-, tetra-, and pentamer (Figure 1). ${ }^{4}$ The crystal structure of the dimer and the optically active tetramer have already been described in Part I of this series. ${ }^{5}$ The dimer is a meso compound with its center of symmetry within the molecule. Its configuration was designated as $(1 S, 5 S, 1 R, 5 R)$ to indicate that the asymmetric $\mathrm{C}(1), \mathrm{C}(5), \mathrm{C}(1)^{\prime}$, and $\mathrm{C}(5)^{\prime}$ atoms are in the $S, S, R$, and $R$ configurations, respectively. The configuration of the optically active tetramer, on the other hand, was designated as $(1 R, 5 S)_{4}$.

The NMR method could not be used to determine whether this optically inactive tetramer was a meso compound or a racemic mixture. Therefore, at the initial stage, this tetramer was assumed to be the meso compound, $(1 R, 5 S, 1 S, 5 R)_{2}$ by analogy with the structure of the dimer. The present study was undertaken in order to establish the configuration of the optically inactive tetramer, and to clarify the mechanism of the oligomerization process.

Aside from the interest in the reaction mechanism, the crystal structure of this compound was of particular interest from the standpoint of the molecular inclusion complex formation. The optically active tetramer forms a molecular inclusion complex with an acetonitrile molecule in the central cavity. Since the polar axis of the acetonitrile mol- 


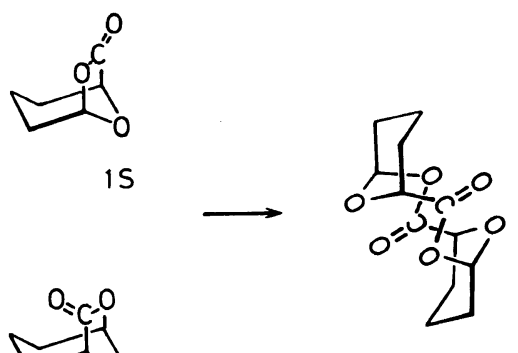

IR

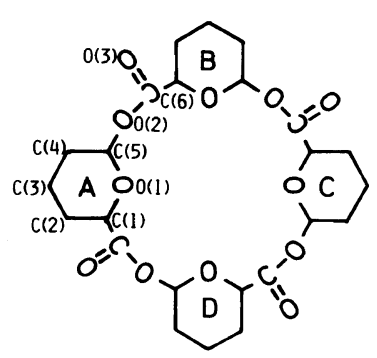

4. $4 R$

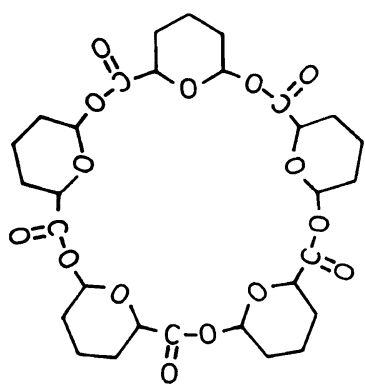

$5,5 R$

Figure 1. 6,8-Dioxabicyclo[3.2.1]octane-7-one and its cyclic oligoesters.

ecule and those of the carbonyl groups of the tetramer are parallel, the dipole-dipole interaction seems to be the main driving force in the formation of this complex. A similar but still different molecular inclusion complex is expected to be formed in the present optically inactive tetramer, since the crystal contains $3 / 2$ acetonitrile molecules per tetramer molecule.

\section{MATERIALS AND METHOD}

The DBOO tetramer from the racemic monomer crystallizes in several different forms depending on the crystallization conditions. ${ }^{5}$ The present crystal was obtained from an acetonitrile solution (Form III). The crystal data are listed in Table I.

Table I. Crystal data

\begin{tabular}{ll}
\hline Chemical formula & $\left(\mathrm{C}_{6} \mathrm{H}_{8} \mathrm{O}_{3}\right)_{4} \cdot 1.5 \mathrm{CH}_{3} \mathrm{CN}$ \\
Formular weight & 574.10 \\
Space group & $\mathrm{C} 2 / c$ \\
Cell constants & $a=44.53(3) \AA$ \\
& $b=5.977(2)$ \\
& $c=22.562(9)$ \\
& $\beta=108.41(3)^{\circ}$ \\
Density & $1.34 \mathrm{~g} / \mathrm{cm}^{3}$ \\
Obsd & $1.338 \quad($ for $Z=8)$ \\
Calcd & \multicolumn{2}{c}{}
\end{tabular}

\section{Data Collection}

Since the crystal deteriorated during the X-ray data collection, four crystal specimens were used. The size of each crystal was about $0.1 \times 0.2 \times 0.4$ $\mathrm{mm}^{3}$. The measurement was made by a Rigaku four-circle diffractometer equipped with a rotating anode X-ray generator. The $\omega-2 \theta$ continuous scan mode was applied using graphite monochromatized $\mathrm{Cu} K \alpha$ with a scan range of $\Delta \omega=1.5^{\circ}+0.142 \tan \theta$. The scan speed was $10^{\circ} / \mathrm{min}$ for all 4602 reflections $\left(2 \theta \leqq 128^{\circ}\right)$. Lorentz and polarization corrections were carried out, but no correction was made for absorption. Each crystal was used until the monitor intensities decayed by $10 \%$. The decay correction was made going on the assumption that the decay mode of the crystal was linearly dependent on X-ray exposure.

\section{Structure Analysis}

Structure was directly determined using the program MULTAN78. ${ }^{6}$ Except for the acetonitrile molecule on the crystallographic two-fold axis, 39 non-hydrogen atoms including an acetonitrile molecule in the cavity of the DBOO tetramer were located on the $E$-map. The remaining three atoms were found on the $\Delta F$ synthesis. The structure was refined by the block-diagonal-least-squares method (HBLS VI). ${ }^{7}$ The function minimized was $\Sigma \omega(\Delta F)^{2}$, with $\omega=\left(\sigma^{2}(F o)+0.295|F o|+0.0857|F o|^{2}\right)^{-1}$ for $|F o|>0$, where $\sigma(F o)$ is the standard deviation based on counting statistics. The final $R$ value was 0.099 for the 3120 reflections of $|F o| \geqq 3 \sigma(F o)$. The atomic scattering factors were taken from International Tables for X-ray Crystallography. ${ }^{8}$ The coordinates and the isotropic thermal factors for the non-hydrogen atoms are listed in Table II. The hydrogen positional parameters, except for those of the methyl groups in acetonitrile, were calculated geometrically and fixed in the refinement. Their coordinates are given in Table III. The iso- 
Crystal Structure of the Cyclic Oligoester

Table II. Atomic positional parameters and their ESD's in parentheses $\left(\times 10^{4}\right)$

\begin{tabular}{|c|c|c|c|c|}
\hline Atom & $x$ & $y$ & $z$ & Beq $/ \AA^{29}$ \\
\hline $\mathrm{C}(1) \mathrm{A}$ & $1867(1)$ & $2417(7)$ & $2171(2)$ & $2.5(2)$ \\
\hline$C(2) A$ & $2052(1)$ & 633(9) & $2623(3)$ & $3.3(2)$ \\
\hline $\mathrm{C}(3) \mathrm{A}$ & $1848(1)$ & $-257(9)$ & 2997(3) & $3.6(2)$ \\
\hline $\mathrm{C}(4) \mathrm{A}$ & $1728(1)$ & $1675(10)$ & $3302(2)$ & $3.6(2)$ \\
\hline$C(5) A$ & $1574(1)$ & $3436(9)$ & $2832(2)$ & $3.0(2)$ \\
\hline$C(6) A$ & $1055(1)$ & $3887(9)$ & 2099(3) & $3.6(2)$ \\
\hline $\mathrm{O}(1) \mathrm{A}$ & $1765(1)$ & $4173(5)$ & $2486(2)$ & $2.9(1)$ \\
\hline $\mathrm{O}(2) \mathrm{A}$ & $1286(1)$ & $2484(6)$ & $2408(2)$ & $3.4(1)$ \\
\hline $\mathrm{O}(3) \mathrm{A}$ & $1049(1)$ & $5811(9)$ & $2223(3)$ & $7.2(3)$ \\
\hline $\mathrm{C}(1) \mathrm{B}$ & $814(1)$ & $2657(9)$ & $1587(2)$ & $3.2(2)$ \\
\hline $\mathrm{C}(2) \mathrm{B}$ & $635(2)$ & $879(11)$ & $1816(3)$ & $4.3(3)$ \\
\hline $\mathrm{C}(3) \mathrm{B}$ & $384(2)$ & $-138(13)$ & $1261(3)$ & $5.3(3)$ \\
\hline $\mathrm{C}(4) \mathrm{B}$ & $173(2)$ & $1685(14)$ & $864(3)$ & $5.1(3)$ \\
\hline $\mathrm{C}(5) \mathrm{B}$ & $371(2)$ & $3430(11)$ & $702(3)$ & $4.2(2)$ \\
\hline $\mathrm{C}(6) \mathrm{B}$ & $608(1)$ & $3743(10)$ & $-118(3)$ & $3.9(2)$ \\
\hline $\mathrm{O}(1) \mathrm{B}$ & $608(1)$ & $4303(6)$ & $1222(2)$ & $3.7(2)$ \\
\hline $\mathrm{O}(2) \mathrm{B}$ & $519(1)$ & $2430(7)$ & $279(2)$ & $3.7(2)$ \\
\hline $\mathrm{O}(3) \mathrm{B}$ & $546(2)$ & $5703(9)$ & $-177(3)$ & $7.5(3)$ \\
\hline $\mathrm{C}(1) \mathrm{C}$ & $787(1)$ & $2404(9)$ & $-451(2)$ & $3.3(2)$ \\
\hline$C(2) C$ & $582(2)$ & $652(12)$ & $-893(3)$ & $4.5(3)$ \\
\hline $\mathrm{C}(3) \mathrm{C}$ & $773(2)$ & $-480(12)$ & $-1243(3)$ & $5.3(3)$ \\
\hline $\mathrm{C}(4) \mathrm{C}$ & $933(2)$ & $1174(12)$ & $-1554(3)$ & $4.6(3)$ \\
\hline $\mathrm{C}(5) \mathrm{C}$ & $1105(1)$ & $2966(10)$ & $-1098(3)$ & $3.7(2)$ \\
\hline $\mathrm{C}(6) \mathrm{C}$ & $1638(1)$ & $3054(10)$ & $-397(2)$ & $3.8(2)$ \\
\hline $\mathrm{O}(1) \mathrm{C}$ & $924(1)$ & $3941(6)$ & $-771(2)$ & $3.5(1)$ \\
\hline $\mathrm{O}(2) \mathrm{C}$ & $1375(1)$ & $1853(6)$ & $-650(2)$ & $3.4(1)$ \\
\hline $\mathrm{O}(3) \mathrm{C}$ & $1679(2)$ & $4845(10)$ & $-593(3)$ & $8.0(3)$ \\
\hline$C(1) D$ & $1857(1)$ & $1832(8)$ & $146(2)$ & $3.0(2)$ \\
\hline$C(2) D$ & $2027(2)$ & $-145(9)$ & $-37(3)$ & $3.8(2)$ \\
\hline$C(3) D$ & $2259(2)$ & $-1164(9)$ & $552(3)$ & $3.9(2)$ \\
\hline$C(4) D$ & $2486(1)$ & $645(10)$ & $915(3)$ & $3.7(2)$ \\
\hline$C(5) D$ & 2301(1) & $2651(8)$ & $1026(2)$ & $2.9(2)$ \\
\hline$C(6) \mathrm{D}$ & $2058(1)$ & $3481(8)$ & $1803(2)$ & $2.7(2)$ \\
\hline $\mathrm{O}(1) \mathrm{D}$ & $2086(1)$ & $3477(6)$ & $488(2)$ & $2.9(1)$ \\
\hline $\mathrm{O}(2) \mathrm{D}$ & $2138(1)$ & $1934(5)$ & $1459(2)$ & $3.0(1)$ \\
\hline $\mathrm{O}(3) \mathrm{D}$ & $2128(1)$ & $5428(6)$ & $1813(2)$ & $4.1(2)$ \\
\hline $\mathrm{C}(1) \mathrm{S}$ & $0(0)$ & $5147(48)$ & $2500(0)$ & $21.6(28)$ \\
\hline$C(2) S$ & $0(0)$ & $7588(30)$ & $2500(0)$ & $8.7(8)$ \\
\hline $\mathrm{N}(1) \mathrm{S}$ & $0(0)$ & $9431(21)$ & $2500(0)$ & $8.0(6)$ \\
\hline $\mathrm{C}(3) \mathrm{S}$ & $1344(4)$ & $7871(15)$ & $973(8)$ & $12.1(8)$ \\
\hline $\mathrm{C}(4) \mathrm{S}$ & $1333(2)$ & $5476(11)$ & $875(3)$ & $4.7(3)$ \\
\hline $\mathrm{N}(2) \mathrm{S}$ & $1341(1)$ & $3645(9)$ & $839(2)$ & $4.4(2)$ \\
\hline
\end{tabular}

tropic thermal factors for the hydrogen atoms were assigned with Beq's of the carrier atoms.*

* The anisotropic thermal factors of the nonhydrogen atoms and a list of the observed and calculated structure factors will be provided by the authors upon request.
Table III. Hydrogen positional parameters and their ESD's in parentheses $\left(\times 10^{3}\right)$

\begin{tabular}{|c|c|c|c|c|}
\hline Atom & $x$ & $y$ & $z$ & Bonded to \\
\hline $\mathrm{H}(1)$ & $167(2)$ & $155(11)$ & $186(3)$ & $\mathrm{C}(1) \mathrm{A}$ \\
\hline $\mathrm{H}(2)$ & $226(2)$ & $136(12)$ & $294(3)$ & $\mathrm{C}(2) \mathrm{A}$ \\
\hline $\mathrm{H}(3)$ & $211(1)$ & $-71(12)$ & $237(3)$ & $\mathrm{C}(2) \mathrm{A}$ \\
\hline $\mathrm{H}(4)$ & $199(2)$ & $-136(12)$ & $335(3)$ & $\mathrm{C}(3) \mathrm{A}$ \\
\hline $\mathrm{H}(5)$ & $165(2)$ & $-114(12)$ & $269(4)$ & $\mathrm{C}(3) \mathrm{A}$ \\
\hline $\mathrm{H}(6)$ & 192(2) & $239(12)$ & $366(4)$ & $\mathrm{C}(4) \mathrm{A}$ \\
\hline $\mathrm{H}(7)$ & $156(2)$ & $102(12)$ & $351(3)$ & $\mathrm{C}(4) \mathrm{A}$ \\
\hline $\mathrm{H}(8)$ & $153(2)$ & $487(11)$ & $308(3)$ & $\mathrm{C}(5) \mathrm{A}$ \\
\hline $\mathrm{H}(9)$ & $94(2)$ & $171(12)$ & $132(3)$ & $\mathrm{C}(1) \mathrm{B}$ \\
\hline $\mathrm{H}(10)$ & $53(2)$ & $158(13)$ & $213(4)$ & $\mathrm{C}(2) \mathrm{B}$ \\
\hline $\mathrm{H}(11)$ & $80(2)$ & $-44(13)$ & $205(4)$ & $C(2) B$ \\
\hline $\mathrm{H}(12)$ & $24(2)$ & $-125(14)$ & $143(4)$ & $\mathrm{C}(3) \mathrm{B}$ \\
\hline $\mathrm{H}(13)$ & $50(2)$ & $-105(14)$ & $98(4)$ & $\mathrm{C}(3) \mathrm{B}$ \\
\hline $\mathrm{H}(14)$ & $3(2)$ & $242(15)$ & $112(4)$ & C(4)B \\
\hline $\mathrm{H}(15)$ & $2(2)$ & $94(14)$ & $44(4)$ & $\mathrm{C}(4) \mathrm{B}$ \\
\hline $\mathrm{H}(16)$ & $22(2)$ & $481(13)$ & $51(4)$ & $\mathrm{C}(5) \mathrm{B}$ \\
\hline$H(17)$ & $97(2)$ & $144(12)$ & $-11(3)$ & $\mathrm{C}(1) \mathrm{C}$ \\
\hline $\mathrm{H}(18)$ & $38(2)$ & $145(14)$ & $-121(4)$ & $\mathrm{C}(2) \mathrm{C}$ \\
\hline $\mathrm{H}(19)$ & $50(2)$ & $-57(14)$ & $-62(4)$ & $\mathrm{C}(2) \mathrm{C}$ \\
\hline $\mathrm{H}(20)$ & $62(2)$ & $-152(15)$ & $-159(4)$ & $\mathrm{C}(3) \mathrm{C}$ \\
\hline $\mathrm{H}(21)$ & $95(2)$ & $-151(14)$ & $-92(4)$ & $\mathrm{C}(3) \mathrm{C}$ \\
\hline $\mathrm{H}(22)$ & $76(2)$ & 194(14) & $-193(4)$ & $\mathrm{C}(4) \mathrm{C}$ \\
\hline $\mathrm{H}(23)$ & $110(2)$ & $29(14)$ & $-171(4)$ & $\mathrm{C}(4) \mathrm{C}$ \\
\hline $\mathrm{H}(24)$ & $117(2)$ & $428(12)$ & $-135(3)$ & $\mathrm{C}(5) \mathrm{C}$ \\
\hline $\mathrm{H}(25)$ & $197(2)$ & $344(11)$ & $18(3)$ & $C(1) D$ \\
\hline $\mathrm{H}(26)$ & $215(2)$ & $43(12)$ & $-33(3)$ & $C(2) D$ \\
\hline $\mathrm{H}(27)$ & $186(2)$ & $-137(12)$ & $-27(4)$ & $C(2) D$ \\
\hline $\mathrm{H}(28)$ & $239(2)$ & $-247(13)$ & 42(4) & $C(3) D$ \\
\hline $\mathrm{H}(29)$ & $213(2)$ & $-186(12)$ & $84(3)$ & $C(3) D$ \\
\hline $\mathrm{H}(30)$ & $264(2)$ & $117(12)$ & $65(3)$ & $C(4) D$ \\
\hline $\mathrm{H}(31)$ & $263(2)$ & $-1(12)$ & $136(4)$ & $\mathrm{C}(4) \mathrm{D}$ \\
\hline $\mathrm{H}(32)$ & $253(2)$ & $321(11)$ & $134(3)$ & $C(5) D$ \\
\hline
\end{tabular}

\section{RESULTS AND DISCUSSION}

\section{Configuration}

The ORTEP ${ }^{10}$ drawings of a $(1 R, 5 S)_{4}$ molecule are given in Figure 2. The present X-ray structure analysis showed that this compound was a racemic mixture of $\left(1 R_{\mathrm{eq}}, 5 S_{\mathrm{ax}}\right)_{4}$ and its enantiomer $\left(1 S_{\mathrm{eq}}\right.$, $\left.5 R_{\mathrm{ax}}\right)_{4}$, rather than a meso compound such as $((1 R$, $\left.5 S)_{2}(1 S, 5 R)_{2}\right)$ with $\overline{1}$ or $(1 R, 5 S, 1 S, 5 R)_{2}$ with $\overline{4}$. This is very important in investigating the oligomerization process. A detailed discussion of the mechanism based on this structure study will be given elsewhere. ${ }^{11}$

\section{Description of Structure}

Bond lengths and angles are given in Figure 3, in 

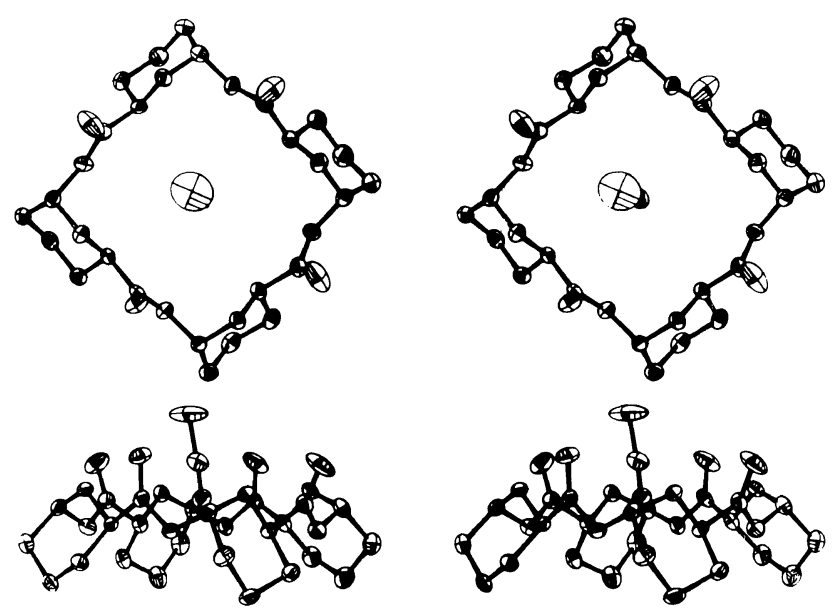

Figure 2. Stereodrawings of the enantiomer $(1 R, 5 S)_{4}$ viewed from a direction parallel to (top) and perpendicular to (bottom) its noncrystallographic four-fold axis. The thermal ellipsoids are drawn at the $30 \%$ probability level.

which only mean values for chemically equivalent bonds are shown, since the molecule was found to have an approximate four-fold symmetry. These values are in good agreement with those for the optically active tetramer, and no significant differences could be observed between the two tetramers. The bond lengths and angles for the acetonitriles are given in Table IV.

The asymmetry of the two $\mathrm{C}-\mathrm{O}$ bond lengths in the tetrahydropyran ring, observed in both the dimer and the optically active tetramer, was also found in this molecule. The lengths of the $\mathrm{C}(1)-\mathrm{O}(1)$ bonds were $1.378(7)-1.407(8)$ with a mean value of $1.391 \AA$ and that of $\mathrm{C}(5)-\mathrm{O}(1)$ was $1.417(7)$ 1.450 (7) with a mean value of $1.427 \AA$.

The conformation angles of one enantiomer $(1 R$, $5 S)_{4}$ are listed in Table V. As for the conformation angles for the six-membered rings, no significant differences could be observed between the present tetramer and the optically active tetramer. There were, however, some differences in the conformation angles of the twenty-membered ring, the maximum differences being $5.0^{\circ}$. These differences were perhaps due to differences in the intermolecular environments.

Except for these differences, the two tetramers have very similar molecular structures. The molecular comparing program (CMRL) ${ }^{12}$ showed that the $(1 R, 5 S)_{4}$ molecule coincided with the optically active tetramer with an RMS deviation of $0.24 \AA$.
The acetonitrile molecule in the central cavity was also included in this calculation. The RMS deviations were $0.22 \AA$ and $0.19 \AA$ when the calculation included only the tetramers and the main rings, respectively.

The molecule was found to have nearly four-fold symmetry, although there were slight differences in the structural parameters of the chemically equivalent bonds. The maximum deviation for the conformation angles was $5.5^{\circ}$. The degree of $\mathrm{C}_{4}$ symmetry was quantitatively examined. As a criterion, the RMS distance between the original coordinates and those rotated by $90^{\circ}, 180^{\circ}$, and $270^{\circ}$ were employed. The RMS distance was $0.13 \AA$ for the optically active tetramer, and $0.19 \AA$ for the present tetramer.

\section{Complexation with Acetonitriles}

As is shown in Figure 2, the racemic DBOO tetramer also accommodates one acetonitrile molecule in its central cavity. The scheme of complexation is completely the same as that of the optically active tetramer as a result of dipole-dipole interaction. However, this is very different from that observed in cyclodextrin or nactins, in which the main rings of the host molecules have considerable flexibility and the shapes of the host molecules change significantly in such a way that the particular atoms of the hosts are coordinated to the guest molecules. ${ }^{13-15}$ In the DBOO tetramer, the main ring has tetrahydropyran rings and ester groups 


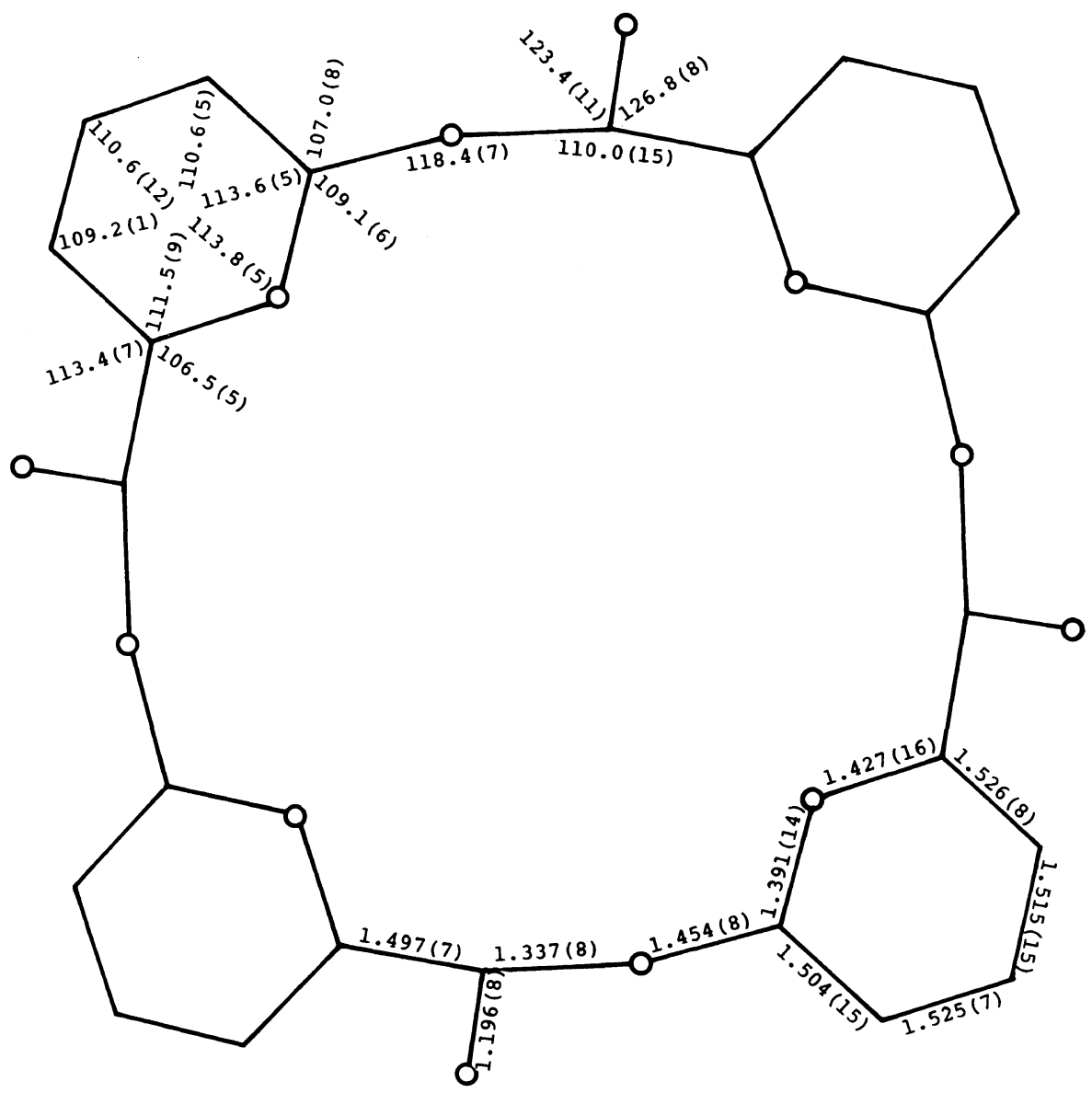

Figure 3. Mean values for the bond lengths (bottom) and the bond angles (top).

Table IV. Bond lengths $(\AA)$ and angles (degree) of the acetonitriles

\begin{tabular}{llll}
\hline $\mathrm{C}(1) \mathrm{S}-\mathrm{C}(2) \mathrm{S}$ & $1.459(34)$ & $\mathrm{C}(3) \mathrm{S}-\mathrm{C}(4) \mathrm{S}$ & $1.447(19)$ \\
$\mathrm{C}(2) \mathrm{S}-\mathrm{N}(1) \mathrm{S}$ & $1.102(22)$ & $\mathrm{C}(4) \mathrm{S}-\mathrm{N}(2) \mathrm{S}$ & $1.099(9)$ \\
$\mathrm{C}(1) \mathrm{S}-\mathrm{C}(2) \mathrm{S}-\mathrm{N}(1) \mathrm{S}$ & $180.0(21)$ & $\mathrm{C}(3) \mathrm{S}-\mathrm{C}(4) \mathrm{S}-\mathrm{N}(2) \mathrm{S}$ & $175.3(10)$ \\
\hline
\end{tabular}

alternatively, so that the tetramer molecule is fairly rigid and its shape does not change very much. Hence, dipole-dipole interaction plays a key role in the formation of these complexes. In the present case, all four carbonyl $\mathrm{C}=\mathrm{O}$ bonds and the $\mathrm{N} \equiv \mathrm{C}$ nitrile group were arranged roughly parallel and located at about the same height along the pseudo four-fold axis, the carbon atom of the nitrile group being within $0.01 \AA$ on the plane formed by the four carbonyl oxygen atoms. The distance between the oxygen atoms of the carbonyl groups and the carbon atom of the nitrile group was from 3.5054.086 (mean value 3.564) $\AA$.

The crystal structure is shown in Figure 4. One more acetonitrile molecule was found on the crystallographic two-fold axis. This acetonitrile molecule was surrounded by six tetramer molecules, and functioned as a spacer by means of weak van- 
Table V. Conformation angles (degree)

20-Membered rings

\begin{tabular}{rrrrrr}
\hline & A & \multicolumn{1}{c}{ B } & C & D & Means \\
\hline $\mathrm{O}(2)-\mathrm{C}(6)-\mathrm{C}(1)-\mathrm{O}(1)$ & $-175.0(4)$ & $-170.6(4)$ & $-169.3(4)$ & $-164.4(4)$ & $-169.8(44)$ \\
$\mathrm{C}(6)-\mathrm{C}(1)-\mathrm{O}(1)-\mathrm{C}(5)$ & $177.7(4)$ & $178.0(5)$ & $178.9(5)$ & $177.4(4)$ & $178.0(6)$ \\
$\mathrm{C}(1)-\mathrm{O}(1)-\mathrm{C}(5)-\mathrm{O}(2)$ & $-63.1(6)$ & $-64.0(6)$ & $-63.7(6)$ & $-62.7(6)$ & $-63.3(6)$ \\
$\mathrm{O}(1)-\mathrm{C}(5)-\mathrm{O}(2)-\mathrm{C}(6)$ & $-80.6(6)$ & $-81.5(7)$ & $-88.3(6)$ & $-80.7(6)$ & $-82.8(37)$ \\
$\mathrm{C}(5)-\mathrm{O}(2)-\mathrm{C}(6)-\mathrm{C}(1)$ & $167.1(4)$ & $173.3(4)$ & $167.0(4)$ & $174.9(4)$ & $170.6(41)$ \\
\hline
\end{tabular}

Tetrahydropyran rings

\begin{tabular}{|c|c|c|c|c|c|}
\hline & A & B & $\mathrm{C}$ & $\mathrm{D}$ & Means \\
\hline $\mathrm{O}(1)-\mathrm{C}(1)-\mathrm{C}(2)-\mathrm{C}(3)$ & $56.7(6)$ & $55.5(7)$ & $54.5(7)$ & $57.5(7)$ & $56.1(13)$ \\
\hline$C(1)-C(2)-C(3)-C(4)$ & $-53.3(7)$ & $-53.5(8)$ & $-51.6(9)$ & $-55.4(8)$ & $-53.5(16)$ \\
\hline$C(2)-C(3)-C(4)-C(5)$ & $51.9(7)$ & $52.1(9)$ & $49.1(9)$ & $52.2(7)$ & $51.3(15)$ \\
\hline $\mathrm{C}(3)-\mathrm{C}(4)-\mathrm{C}(5)-\mathrm{O}(1)$ & $-53.0(7)$ & $-52.6(8)$ & $-49.3(8)$ & $-53.1(7)$ & $-52.0(18)$ \\
\hline $\mathrm{C}(4)-\mathrm{C}(5)-\mathrm{O}(1)-\mathrm{C}(1)$ & $56.5(6)$ & $55.9(7)$ & $54.1(7)$ & $56.8(6)$ & $55.8(12)$ \\
\hline $\mathrm{C}(5)-\mathrm{O}(1)-\mathrm{C}(1)-\mathrm{C}(2)$ & $-58.6(6)$ & $-56.9(7)$ & $-56.7(7)$ & $-58.9(6)$ & $-57.8(11)$ \\
\hline
\end{tabular}

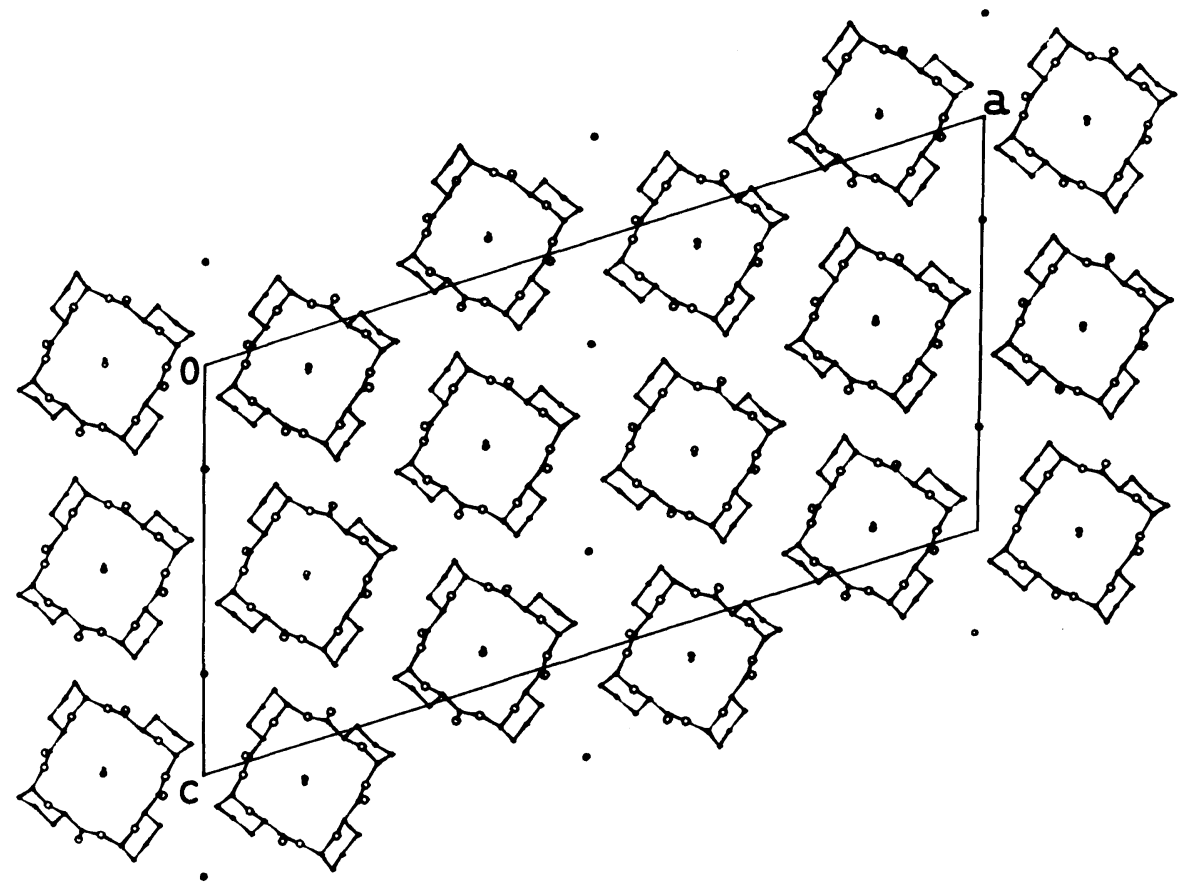

Figure 4. The crystal structure viewed along the $b$ axis. The small dots located at the central cavity of the tetragonal molecules and at the sites of two-fold axes are the acetonitrile molecules set on edge.

der-Waals interactions with the surrounding tetrahydropyran rings. The distance between the nitrile nitrogen and the $\mathrm{C}(3)$ atoms of the tetrahydropyran rings was from $3.72-3.76$ (mean value 3.74 ) $\AA$. Since the acetonitrile molecule itself did not take on a two-fold axal symmetry, it was either rotating 
about the axis or variously oriented to satisfy statistically the requirements of two-fold symmetry. The hydrogen atoms of this molecule could not be found. Such a disordered state may be responsible for the decay of the crystal observed during the Xray experiments.

Acknowledgment. This work was supported in part by a Grant-in-Aid for Scientific Research No. 434024 from the Ministry of Education, Science and Culture of Japan.

\section{REFERENCES}

1. M. Okada, H. Sumitomo, and Y. Yamamoto, Makromol. Chem., 175, 3023 (1974).

2. M. Okada, H. Sumitomo, and I. Tajima, Macromolecules, 10, 505 (1977).

3. M. Okada, H. Sumitomo, and I. Tajima, Polym. Bull., 1, 41 (1978).

4. M. Okada, H. Sumitomo, and I. Tajima, J. Am. Chem. Soc., 101, 4013 (1979).

5. I. Tanaka, I. Tajima, Y. Hayakawa, M. Okada, M. Bitoh, T. Ashida, and H. Sumitomo, J. Am. Chem.
Soc., 102, 7873 (1980).

6. P. Main, S. E. Hull, L. Lessinger, G. Germain, J-P. Declercq, and M. M. Woolfson, "MULTAN 78, a System of Computer Programs for the Automatic Solution of Crystal Structure from X-ray Diffraction Data," Univ. of York, England, and Louvain, Belgium.

7. T. Ashida, "UNICS-Nagoya," The Computation Center, Nagoya University, 1981, p 65.

8. "International Tables for X-ray Crystallography," Vol. IV, Kynoch Press, Birmingham, England, 1974.

9. W. C. Hamilton, Acta Crystallogr., 12, 609 (1959).

10. C. K. Johnson, "ORTEP II," Report ORNL-5138, Oak Ridge National Laboratory, Oak Ridge, Tenn., 1976.

11. M. Okada, H. Sumitomo, and I. Tajima, Macromolecules, 14, 1180 (1981).

12. H. Itoh, "UNICS-Nagoya," The Computation Center, Nagoya University, 1981, p 95.

13. W. Saeger, K. Beyer, and P. C. Manor, Acta Crystallogr., Sect. B, 32, 120 (1976).

14. Y. Nawata, T. Sakamaki, and Y. Iitaka, Acta Crystallogr., Sect. B, 30, 1047 (1974).

15. K. Neupert-Laves and M. Dobler, Helv. Chim. Acta, 59, 614 (1976). 